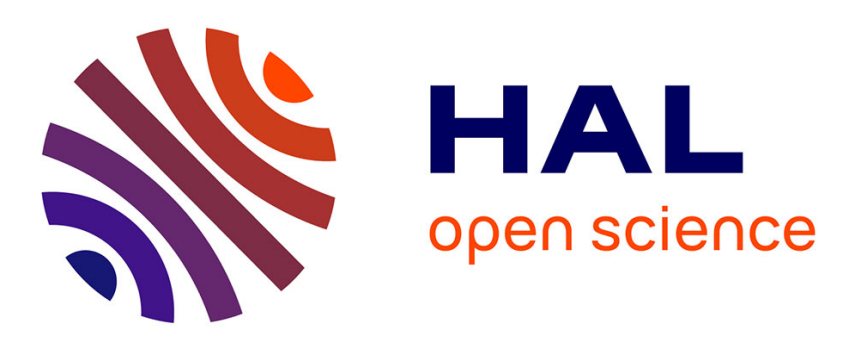

\title{
Shoulder movements during the initial phase of learning manual wheelchair propulsion in able-bodied subjects.
}

\author{
Laurence Roux, Sylvain Hanneton, Agnès Roby-Brami
}

\section{To cite this version:}

Laurence Roux, Sylvain Hanneton, Agnès Roby-Brami. Shoulder movements during the initial phase of learning manual wheelchair propulsion in able-bodied subjects.. Journal of Clinical Biomechanics, 2006, 21, Suppl 1:S45-51. Epub 2005 Nov 7. hal-00021098

\section{HAL Id: hal-00021098 \\ https://hal.science/hal-00021098}

Submitted on 17 Mar 2006

HAL is a multi-disciplinary open access archive for the deposit and dissemination of scientific research documents, whether they are published or not. The documents may come from teaching and research institutions in France or abroad, or from public or private research centers.
L'archive ouverte pluridisciplinaire HAL, est destinée au dépôt et à la diffusion de documents scientifiques de niveau recherche, publiés ou non, émanant des établissements d'enseignement et de recherche français ou étrangers, des laboratoires publics ou privés. 


\title{
Shoulder movements during the initial phase of learning manual wheelchair propulsion in able- bodied subjects
}

\author{
Laurence Roux ${ }^{a}$, Sylvain Hanneton ${ }^{a}$ and Agnès Roby-Brami ${ }^{b}$
}

a) Laboratoire « Cognition et Motricité », JE 2378, UFR STAPS Université René Descartes. 1, rue Lacretelle 75015 Paris. France

b) Laboratoire de Neurophysique et Physiologie, UMR 8119, CNRS and Université René Descartes. 45 rue des Saints Pères 75270 Paris CEDEX 06. France

\begin{abstract}
Background. The kinetics and kinematics of the glenohumeral joints, and shoulder muscles activities during the initial phase of learning wheelchair propulsion by individuals with paraplegia have been partially described. But no studies carry out the kinematics of the upper-limb during the learning of non constrained open field locomotion with a wheelchair.

Methods. Ten subjects with no manual wheelchair experience propelled themselves repetitively straight ahead along an 11 meters linear path. Upper-limb segment orientations were measured with an electromagnetic system. Angular displacements of joints were determined using a standardized protocol (Wu et al., 2005) and modeling method (Biryukova et al.,, 2000).

Findings. A full 3-D scapular motion description was obtained that allowed us to measure the mean amplitudes of rotation for the nine degrees of freedom of our model. The change in the propulsion pace and the repetition of trials induced a general increase of amplitudes of joint rotations that can explain the increase of velocity among trials.

Interpretation. This work is the first to study the kinematics of shoulder joint rotations during the learning of wheelchair propulsion in an ecological situation. We did not observe a freezing of any DOF as predicted by Bernstein's theory of motor learning, but the increase in joint movement amplitudes could correspond to his "unfreezing of DOF" stage. This non-respect of Bernstein's theory could originate in the relative simplicity of the task.
\end{abstract}

Keywords: shoulder - three dimensional kinematics - wheelchair propulsion electromagnetic tracking device- biomechanics - motion capture - learning.

\section{Introduction}

The use of a wheelchair requires the learning of new coordination and the integration of the dynamic properties of this tool. Subjects that are naive to this mode of propulsion are able to adopt spontaneous propulsion strategies rapidly.. The study of the body movements and especially upper limbs movements during manual wheelchair propulsion interests at least three different research fields. First, from a fundamental point of view, learning the use of a wheelchair is an example of integration of a very common propulsive prosthesis that induces a new coupling between the user and his environment. The study of the acquisition of this coupling concerns the motor learning research field but also Ergonomics with the aim to 
improve efficiency, comfort and security in wheelchair design. And finally, since shoulder pathologies are quite common for people having an extensive use of wheelchairs (Subbarao et al., 1995) the study of the biomechanics of the upper limb during wheelchair propulsion has a clinical justification.

Previous wheelchair propulsion studies concerned kinematics (Boninger et al., 2002), biomechanical efficiency (De Groot et al., 2003a), muscle activities (De Groot et al., 2003b), physiology (van der Woude et al., 2001). Some training studies have been performed in the past, in which mechanical efficiency and propulsion technique were evaluated after a period of training (Dallmeijer et al.1999; Rodgers et al., 2001; van der Woude et al., 1999). A 6-weeks training intervention (including stretching, strengthening and aerobic exercise) of wheelchair users led to decreased stroke frequency, increased maximum elbow extension angle, increased trunk and shoulder range of motion, and increased wrist extension moment (Rodgers et al., 2001). However, only few studies take into account the scapular contribution to the propulsive role of the arm and these studies were made with ergometer wheelchairs (Laboisse et al., 1999), or under static conditions (VanderHelm \& Veeger, 1996). Using an electromagnetic motion capture device, we propose to study the contribution of the shoulder complex to wheelchair manual propulsion and especially the progressive mobilization of joints during learning in an ecological situation. Concerning the motor correlates of learning, we propose to inspire us with the way in which Bernstein (1967) describes the stages of learning of a new coordination. According to Bernstein's theory, learning should comprise three stages. The first stage is characterized by the freezing of the limb and the trunk during the execution of the movements. A second phase consists in a release of the degrees of freedom whereas the third corresponds to the optimisation of the acquired strategy.

The aims of this study are (1) to test a method based on the estimation of a kinematical model of the upper limb including the shoulder complex (2) to describe the movements of the joints of the upper limb (and especially the motion of the scapula) during manual wheelchair propulsion in an ecological situation of non constrained open field locomotion, (3) to study the influence of the velocity on kinematics, (4) to study the influence of the repetition on kinematics in order to describe learning or adaptation effects on kinematics during the acquisition of this new coordination. Do learning effects verify Bernstein's theory?

\section{Methods}

\section{Instruments and calibration}

Real time 3-D position and orientation of each subject's thorax, scapula and humerus were tracked at 30$\mathrm{Hz}$ sampling rate by the Polhemus Fastraka electromagnetic device. The reported root mean square (RMS) accuracy of this system is $0.3-0.8 \mathrm{~mm}$ for position, and $0.15^{\circ}$ for orientation when used within a $76 \mathrm{~cm}$ source to sensor separation (SPACE FASTRAK User's Manuel, Revision F. Colchester, VT; Polhemus Inc; 1993). The transmitter was fixed on the base of the back of the wheelchair and the FASTRAK device on a small cart pushed by an assistant during the propulsion. Surface electromagnetic sensors were attached to the subjects' skin overlying the sternum (on the manubrium) and the flat superior bony surface of the scapular acromion process using double-sided adhesive tape secured with sticking-plaster (Karduna et al. 2001). The humeral sensor was attached to the arm via an adapted Velcro straps, $15 \mathrm{~cm}$ below acromion. A fourth sensor mounted on a pointer manually digitized anatomic landmarks coordinates and was then fixed on the forearm just before the wrist joint. Ten bony landmarks of the thorax and shoulder girdle were palpated and subsequently touched by the pointer tip, while the subject was in the resting position. The position and orientation of the fourth sensor were recorded together with the other receivers on the thorax and the humerus. Digitization allowed to obtain the three dimensional positions of each bony landmark in the global coordinate system (GCS), then in the local coordinates of its correspondent segment sensor according to a global to local matrix transformation, as was described in detail before (Meskers et al., 1998). The bony landmarks coordinates were used to define relevant local anatomic coordinate systems for each segment, (Veeger et al., 1993). In addition to this, for the humerus, the tuberculum majus, was digitized and the 
glenohumeral center was estimated according to the method described by Biryukova et al. (2000). For that purpose, subjects have to execute height like movements of the upper limb during 5 seconds.

\section{Definition of segment orientations}

For this study, the orientation of the thorax relative to the GCS, and the orientation of the scapula and the humerus relative to the thorax were analyzed. The standardized sequence of Euler angles proposed by Van der Helm was chosen to allow for comparison of results. Thorax orientation was described using the $X Z^{\prime} Y^{\prime \prime}$ Euler sequence. Forward/backward rotation was about the global $\mathrm{X}$-axis followed by lateral flexion about the thoracic $Z^{\prime}$-axis (horizontal, pointing backward), followed by torsion about the thoracic $Y^{\prime \prime}$-axis (vertical, pointing upward). Scapular orientation was described using the $Y Z^{\prime} X^{\prime \prime}$ Euler sequence. Protraction/retraction was about the thoracic Y-axis, followed by elevation/depression around the scapula $Z^{\prime}$-axis (perpendicular to the scapular plane, pointing backward), followed by anterior/posterior tilt around the scapular X"'-axis through the scapular spine. These geometrical definitions are consistent with the usual clinical descriptions of scapular motion: Protraction is produced by the gliding of the scapula around the curved chest away from the vertebral column; lateral rotation is usually defined as the movement of the glenoid fossa superiorly while the inferior angle of the scapula moves laterally and upward; and anterior tilt as the movement of the inferior angle of the scapula away from the thorax. Humeral orientation relative to the thorax was described using the $\mathrm{YZ}^{\prime} \mathrm{Y}^{\prime \prime}$ sequence including plane of elevation with respect to the thoracic Y-axis, humeral elevation/depression about the local $Z^{\prime}$-axis, and axial rotation about the local $Y^{\prime \prime}$-axis. The angular position of the elbow was estimated by the solid angle between the humerus (Y-axis) and the axis of the fourth sensor aligned with the forearm (sensor X-axis).

\section{Subjects and experimental procedures}

One group of ten young able-bodied subjects (four females and six males without any shoulder disorder), who never experienced the wheelchair propulsion participated in our study Mean age was 23 years $(\mathrm{SD}=3.23)$, mean weight was $64.8 \mathrm{~kg}(\mathrm{SD}=7.86)$ and mean height was $1.72 \mathrm{~m}(\mathrm{SD}=6.50)$. All subjects were right-handed. We used for this study a sport wheelchair made with aluminium in order to avoid disturbances of the electromagnetic field produced by the motion capture device. Before propulsion trials, we pointed with the fourth sensor the anatomical landmarks and subjects were asked to make simple movements in order to estimate the position of the center of rotation of the gleno-humeral joint. Then subjects were instructed to propel themselves straight ahead along a 11 meters linear path. They drove six consecutive trials at a "normal comfortable" speed and six trials at a "higher" speed. We recorded run durations with a hand-held standard chronometer to estimate the average velocity.

\section{Data analysis}

For each trial propulsion, cycles were sequenced according to the 3D trajectory of the sensor fixed on the wrist. The push and the recovery phases were defined as beginning and ending with a minimum of the norm of the tangential velocity of this sensor.

Variables of interest were on one hand the temporal characteristics of each cycle (cycle duration, relative duration of the push phase, cycling frequency) and on the other hand the maximal, minimal and mean amplitude of rotation for each degree of freedom. The trial number and the requested paces were considered respectively as six levels (TRIAL factor) and two levels (PACE factor) repeated measures factors for the subsequent analyses of variance.

\section{Results}

Figure 1 shows a typical example of the evolution of the trunk flexion-extension and the scapulothoracic and gleno-humeral rotations and elbow (from top to bottom) during the first four cycles of 
wheelchair propulsion in a representative subject at a normal speed. The vertical lines indicate the limits of the push (A) and recovery (B) phases determined by the trajectory of the sensor fixed on the wrist (not shown). The first cycle begin by the push phase followed by the recuperation phase. Most of the recorded DOF participated in the movement, their rotation amplitude increased rapidly to attain a regular steady state at the third cycle.

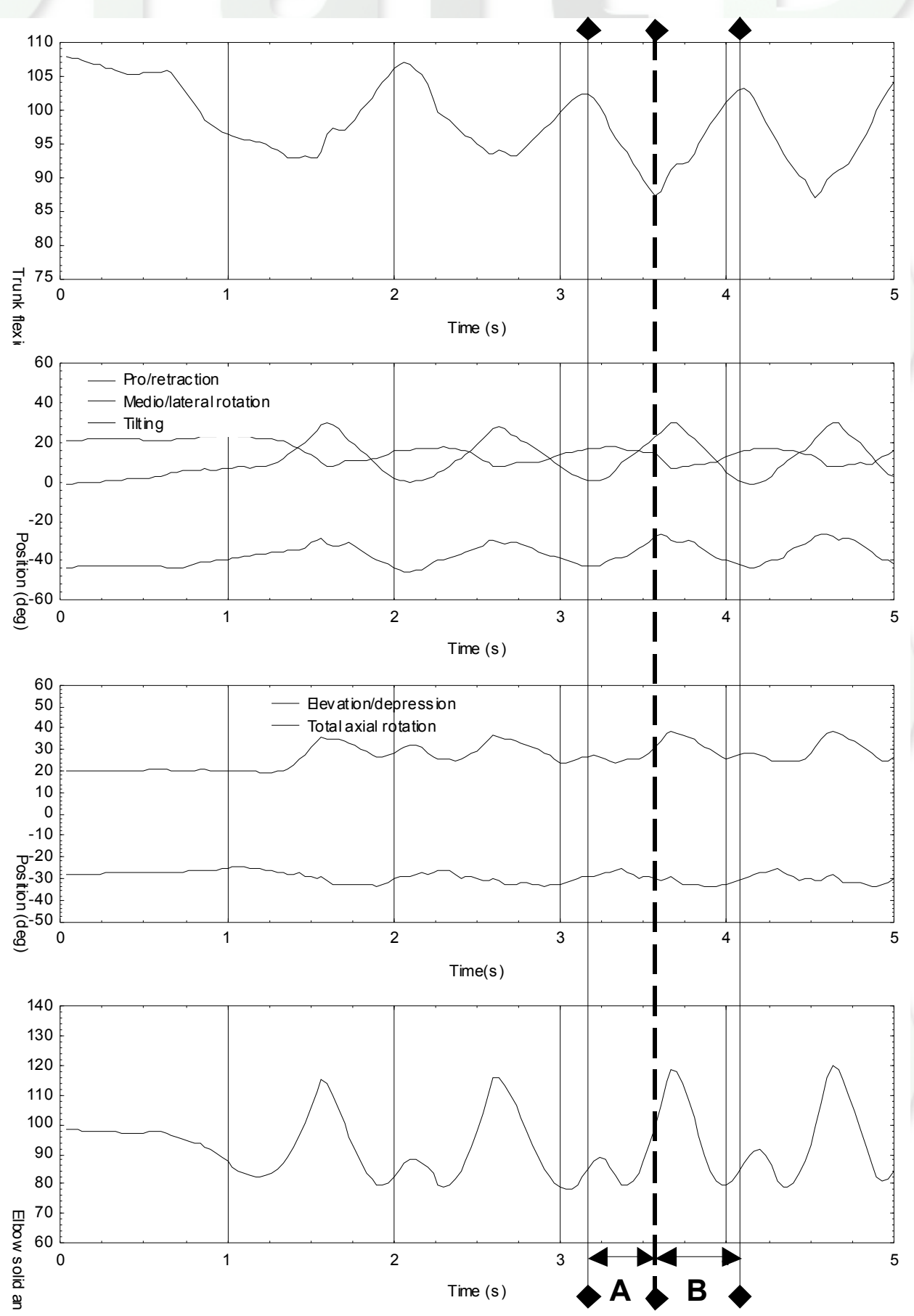

Figure 1. Kinematics data for the five first seconds of a sample trial. From top to bottom are figured in degrees the temporal evolution of joint angles for the trunk, the scapula, the humerus and the elbow. The two phases of one propulsion cycle are emphasized by three vertical lines : the push phase (A) and the recovery phase (B). For the trunk (top), a decrease of the curve corresponds to an increase of the flexion.

We compared the evolution of the frequency of the cycles of propulsion during trials at normal speed 
and at fast speed. Trial duration was obviously shorter for the "higher" velocity and decreased among trials for both requested paces. As expected, the average velocity is higher for the fast speed condition (mean 1.51 $\mathrm{m} / \mathrm{s}, \mathrm{SD}=0.15 \mathrm{~m} / \mathrm{s}$ ) than for the normal speed (mean $1.09 \mathrm{~m} / \mathrm{s}, \mathrm{SD}=0.16 \mathrm{~m} / \mathrm{s}$ ). Both PACE and TRIAL factors were shown to influence significantly the average velocity (respectively $F[1,8]=122, p<0.0001$ and $F[5,40]$ $=10.1 ; \mathrm{p}<0.0001$ ). Despite the apparent differences, for the two requested paces the cycle frequency could not be shown to decrease among trials. There was no correlation between the trial duration and the cycle frequency. We observed a small but significant decrease of the relative duration of the push phase within the cycle for both paces into trials (respectively $\mathrm{r}=0.29 ; \mathrm{p}<0.0001$ and $\mathrm{r}=0.35, \mathrm{p}<0.0001$ ). But there was no significant evolution of this mean proportion among trials. The observed velocity increase was indeed not due to changes in temporal characteristics of cycles.

\begin{tabular}{|c|c|c|c|c|c|c|c|}
\hline \multirow[b]{2}{*}{ Joints } & \multirow{2}{*}{$\begin{array}{l}\text { Degrees of } \\
\text { freedom }\end{array}$} & \multicolumn{2}{|c|}{$\begin{array}{c}\text { (A) normal speed } \\
(1.09 \mathrm{~m} / \mathrm{s}, \mathrm{SD}=0.15)\end{array}$} & \multicolumn{2}{|c|}{$\begin{array}{c}\text { (B) higher speed } \\
(1.51 \mathrm{~m} / \mathrm{s}, \mathrm{SD}=0.16)\end{array}$} & \multirow[b]{2}{*}{ (C) PACE factor } & \multirow[b]{2}{*}{ (D) TRIAL factor } \\
\hline & & $\begin{array}{c}\text { Mean } \\
\text { amplitude } \\
\text { (deg) }\end{array}$ & $\begin{array}{c}\text { Standard } \\
\text { error } \\
\text { (deg) }\end{array}$ & $\begin{array}{c}\text { Mean } \\
\text { amplitude } \\
\text { (deg) }\end{array}$ & $\begin{array}{l}\text { Standard } \\
\text { error } \\
\text { (deg) }\end{array}$ & & \\
\hline trunk & $\begin{array}{c}\text { Forward/backward } \\
\text { rotation }\end{array}$ & 10.00 & 2.00 & 15.05 & 3.00 & $\begin{array}{l}\mathrm{F}[1,7]=11 \\
\mathrm{P}<0.013 *\end{array}$ & $\begin{array}{l}F[5,35]=5.21 \\
P<0.0012 *\end{array}$ \\
\hline elbow & Flexion/extension & 42.70 & 4.05 & 57.47 & 8.05 & $\begin{array}{l}\mathrm{F}[1,7]=7.8 \\
\mathrm{P}<0.027 \star\end{array}$ & $\begin{array}{c}\mathrm{F}[5,35]=3.39 \\
\mathrm{P}<0.014 \star\end{array}$ \\
\hline \multirow{2}{*}{$\begin{array}{c}\text { Gleno- } \\
\text { humeral } \\
\text { joint }\end{array}$} & $\begin{array}{l}\text { Elevation } \\
\text { /depression }\end{array}$ & 20.13 & 3.01 & 21.55 & 3.13 & NS & $\begin{array}{c}\mathrm{F}[5,35]=3.12 \\
\mathrm{P}<0.02 \star\end{array}$ \\
\hline & Axial rotation & 41.38 & 3.58 & 49.91 & 2.73 & $\begin{array}{c}\mathrm{F}[1,7]=11.2 \\
\mathrm{P}<0.013 *\end{array}$ & $\begin{array}{c}F[5,35]=3.65 \\
P<0.01 \star\end{array}$ \\
\hline \multirow{3}{*}{$\begin{array}{c}\text { scapulo- } \\
\text { thoracic } \\
\text { joint }\end{array}$} & pro/retraction & 31.30 & 3.27 & 37.31 & 2.61 & $\begin{array}{c}\mathrm{F}[1,7]=25.6 \\
\mathrm{P}<0.002 *\end{array}$ & $\begin{array}{c}\mathrm{F}[5,35]=3.36 \\
\mathrm{P}<0.014 \star\end{array}$ \\
\hline & $\begin{array}{c}\text { medio/lateral } \\
\text { rotation }\end{array}$ & 8.71 & 1.49 & 11.08 & 1.81 & $\begin{array}{c}\mathrm{F}[1,7]=13.72 \\
\mathrm{P}<0.008^{*}\end{array}$ & $\begin{array}{c}\mathrm{F}[5,35]=10.64 \\
\mathrm{P}<0.0001 *\end{array}$ \\
\hline & Tilting & 13.17 & 1.42 & 13.59 & 1.45 & NS & $\begin{array}{c}F[5,35]=5.64 \\
P<0.0007 \star\end{array}$ \\
\hline
\end{tabular}

Table 1. This table give the mean amplitude and the standard error for (A) the "normal comfortable velocity" and (B) the "higher velocity" paces for motion of the different degrees of freedom (second column). The significance of the influence of the (C) PACE and (D) TRIAL factors on the mean amplitudes are given in the two last columns. Mean amplitudes are systematically higher in the "higher speed" condition than in the "normal speed" condition. The TRIAL factor is shown to influence significantly the mean amplitudes of motion for all the degrees of freedom.

Figures two and three present the evolution of the mean amplitude, for each rotation of each joint and for trials in normal speed and higher speed. Mean amplitudes increased progressively among trials, but these evolutions were not the same for all joints and all degrees of freedom. The influence of the TRIAL factor was significant for all the degrees of freedom (table 1). We also compared the mean amplitudes and standard errors of rotations between the normal and the higher speed. As show in table 1, for all joints mean amplitudes are relatively greater for higher speed than for normal speed. Finally, we computed the increase as a percentage of the amplitudes between the first trial and the last one at normal speed and higher speed. The forward and backward rotation of the trunk, the scapulo-thoracic elevation/depression and the scapulothoracic tilting exhibited the greatest increases.

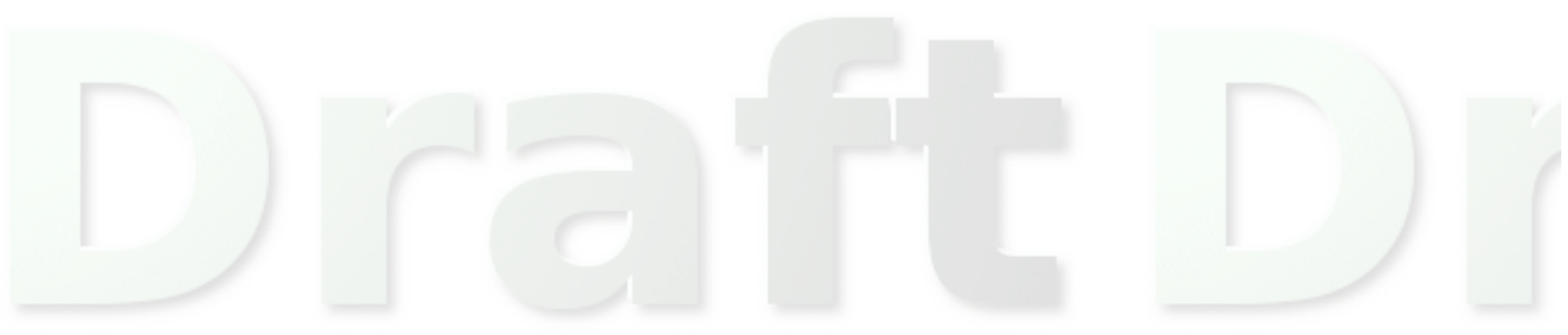



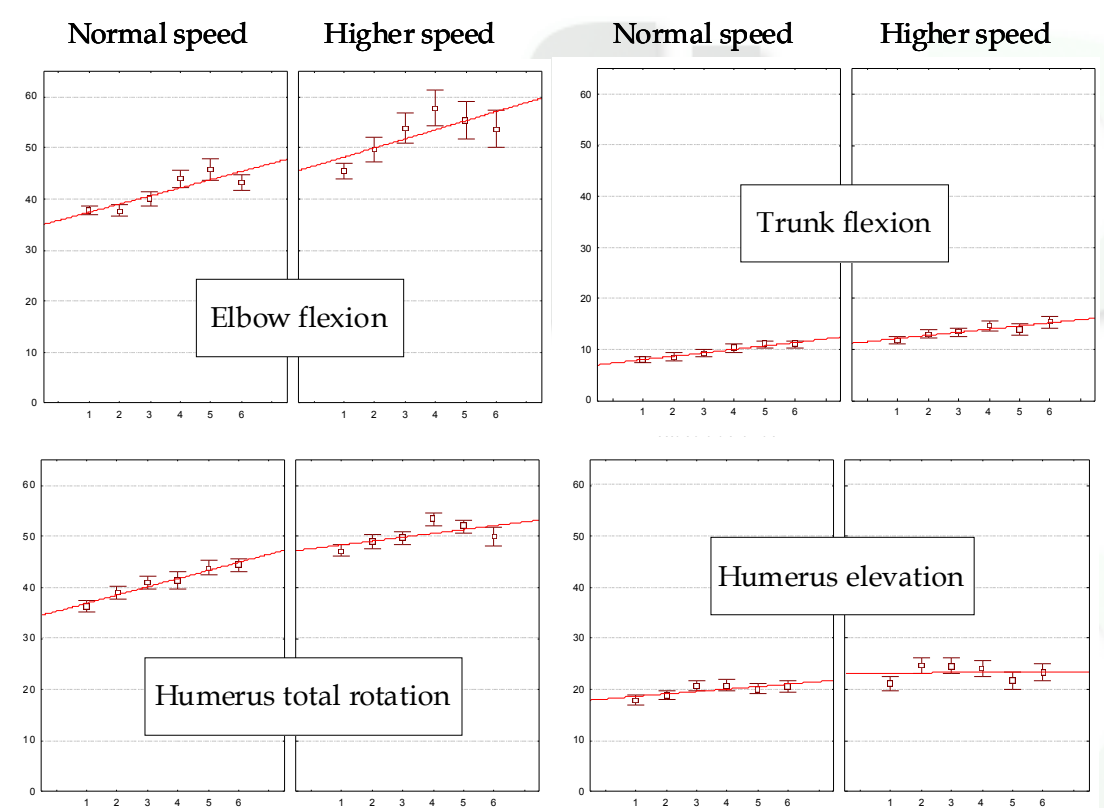

Figure 2. Evolution of the amplitudes of joint degrees of freedom (trunk, humerus and elbow) among trials for the two paces. The humerus "total elevation" refers to the sum of the two Euler angles representing the rotation of the humerus around the Y-axis.
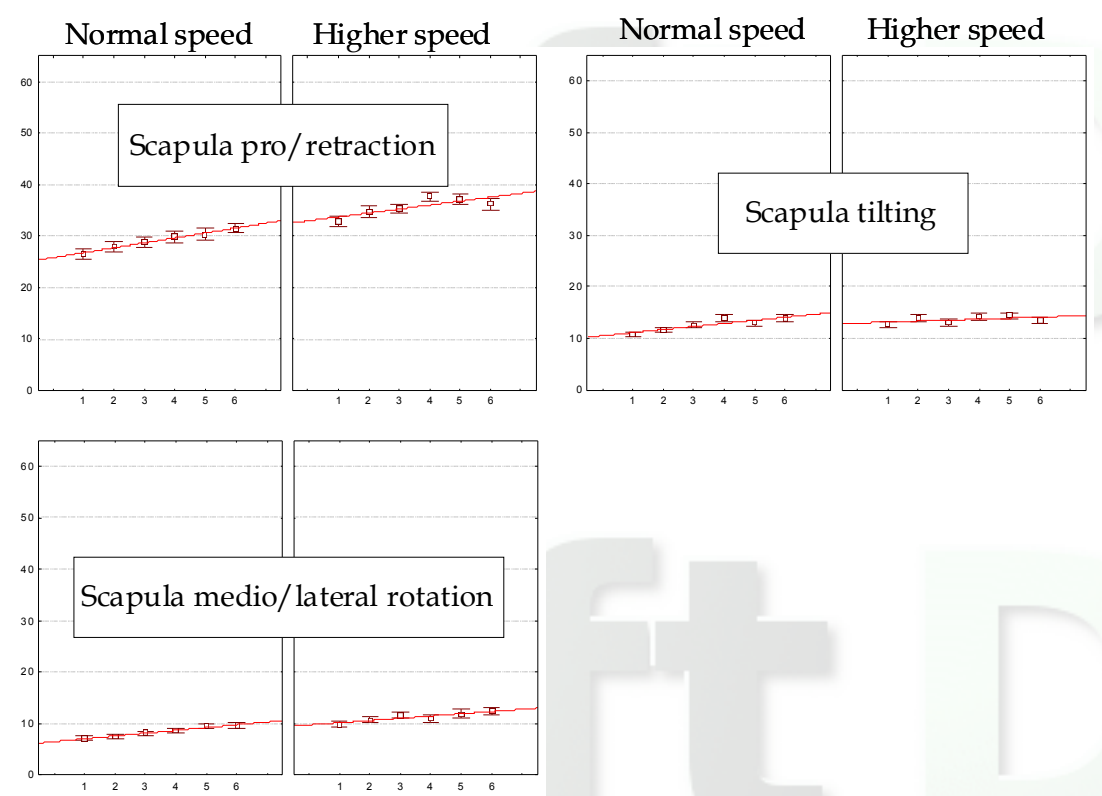

Figure 3. Evolution of the amplitudes of the degrees of freedom of the scapula among trials for the two paces.

\section{Discussion}

This study confirms that a coherent observation and modelling of the upper arm movements can be carried out with electromagnetic motion capture devices even in ecological experimental conditions. We did not observe any perturbation of the electromagnetic field by the wheelchair. This motion capture method, combined with the method proposed by Biryukova et al. to identify the center of rotation of the glenohumeral joint, allowed us to record the motion of nine degrees of freedom during the early phase of wheelchair propulsion learning of body-able subjects. The method proposed here is particularly interesting 
because it allows the dynamic study of the scapular motion, whereas this was previously done using regression equations (Veeger et al., 2002) or quasi-static approximations (van der Helm \& Veeger, 1996). The scapula is indeed shown to be extensively mobilized during the wheelchair propulsion. For instance its range of motion for the pro/retraction that can be up to about $35^{\circ}$ for the high velocity trials. The same protocol could be used for the clinical (functional) evaluation of shoulder pathologies or for the study of compensation strategies of paraplegic patients suffering a shoulder pathology.

The propulsion pace was shown to increase the range of motion of five over the seven studied degrees of freedom whereas the cycle frequency is not significantly affected by the requested pace. The increase of the propulsion velocity seems to be mainly due to an increase of the range of motion of joints. A visible effect of learning is a decrease of trial durations. However a significant increase of amplitudes of joint rotations was the only kinematical correlate of learning. We have to emphasize that subjects were not instructed to increase their velocity from trial to trial however it was the case. Clearly, this increase was not due to a change in the cycle frequency that slightly decreases. The relative duration of the push phase within a cycle slightly decreased as was also found by de Groot et al., (2004). Consequently the velocity increase originates from either an increase of propulsion torque or an increase of amplitudes of movements. Up to now, there have been very few studies focusing on the relationship between changes in mechanical efficiency and changes in co-ordination as a consequence of practice. In repetitive gross motor tasks, such as crawling (Sparrow et al., 1987) and ergometer rowing (Sparrow et al., 1999), it was suggested that movements tend to increase in amplitude and decrease in frequency with practice and that their adaptations lead to a higher (mechanical) efficiency. Our results are in accordance with these observations obtained with other motor tasks. Further analyses of our data must be done, especially the comparison of the temporal kinematical parameters between all subjects. It will be interesting to study the effect of learning with a greater number of repetitions. One can for instance imagine that practice could induce sudden changes in patterns of propulsion for instance. Experience seems to influence both energy cost and technique in wheelchair propulsion, as can be derived from cross-sectional wheelchair studies (Brown et al., 1990; Knowlton et al., 1981; Patterson et al., 1997; Tahamont et al., 1986). Consequently, precious information could be obtained from the comparison of shoulder kinematics between novice wheelchair users and experts (like professional sportsmen).

According to Bernstein's theory we should observe during a very early part of learning a freezing of some degrees of freedom, and a release in a second part. Our data show only a global release of the joints amplitudes. We noticed that during learning the scapulo-thoracic joint acquired a greater importance in wheelchair propulsion. However, we did not identify the "freezing" part of Bernstein's stages. This could be explained by the fact that even if there are a lot of "internal" degrees of freedom involved in the propulsion, the push phase is almost a one DOF task whereas the recovery phase can be considered as a 2 DOF task. This incomplete matching of Bernstein's hypothesis could indeed originate from the low complexity (from a mechanical point of view) of the proposed propulsion task .

\section{References}

Biryukova, E.V., Roby-Brami, A., Frolov, A.A., Mokhtari, M., 2000. Kinematics of human arm reconstructed from spatial tracking system recordings. Journal of Biomechanics. Vol 33, 985-995.

Bernstein, N., 1967. The co-ordination and regulation of movements. Oxford : Pergamon Press.

Boninger, M.L., Souza, A.L., Cooper, R.A., Fitzgerald, S.G., Koontz, A.M. and Fay, B.T., 2002. Propulsion patterns and pushrim biomechanics in manual wheelchair propulsion. Arch. Phys. Med. Rehabil. 83(5):718-723.

De Groot, S., Veeger , H.E.J., Hollander, A.P. and van der Woude, L.H.V, 2003a. Adaptations in physiology and propulsion technique during the initial phase of learning manual wheelchair propulsion. Am. J. Phys. Med. \& Rehab. 82(7):504-510.

Dallmeijer, A.J., van der Woude, L.H.V. and Pathuis, C.S., 1999. Adaptations in wheelchair propulsion technique after training in able-bodied subjects. In Biomedical aspects of manual wheelchair propulsion. The state of 
the art II. Edited by van der Woude L.H.V., Hopman, M.T.E., van Kemenade, C.H. Amsterdam IOS Press.

De Groot, S., Veeger , H.E.J., Hollander, A.P. and van der Woude, L.H.V, 2003b. Short-term adaptations in coordination during the initial phase of learning manual wheelchair propulsion. J. of Electromyogr. Kinesiol. 13:217228.

Karduna, A.R., McClure, P.W., Michener, L.A., Sennett, B. J., 2001. Dynamic measurements of threedimensional scapular kinematics: a validation study. Biomech Eng. 123(2):184-90.

Kotajarvi, B., Brasford, J., Kai-Nan An, 2002. Upper-Extremity Torque Production in Men With Paraplegia Who Use Wheelchair. Arch Phys Med Rehabil. Vol 83, 441-446.

Laboisse, J.-J., Pillu, M., Bourguignon, C., Massieux, M., 1999. Cinématique du membre supérieur au cours de l'utilisation d'un fauteuil roulant par goniométrie électromagnétique. Ann. Kinésithér. Vol.26, Nº6, 242-250.

Rodgers, M.M., Keyser, R.E., Rasch, E.K., Gorman, P.H. and Russel, P.J., 2001. Influence of training on Biomechanics of wheelchair propulsion. J. Rehabil. Res. Dev. 38(5):505-511.

Subbarao, J.V., Klopfstein, J., Turpin, R., 1995. Prevalence and impact of wrist and shoulder pain in patients with spinal cord injury. J Spinal Cord Med 18 (1): 9-13.

Veeger, H.E.J., Rozendaal, L.A., van der Helm, F.C.T., 2002. Load on the shoulder in low intensity wheelchair propulsion. Clin. Biomech. 17:211-218.

Veeger, H.E.J., van der Helm, F.C.T., and Rozendal, R.H., 1993. Orientation of the scapula in a simulated wheelchair push. Clin. Biomech. 8:81-90.

Van der Helm, F.C.T. and Veeger, H.E.J., 1996. Quasi-static analysis of muscle forces in the shoulder mechanism during wheelchair propulsion. J. Biomechanics 29(1):39-52.

Van der Woude, L.H.V., Veeger H.E.J., Dallmeijer, A.J., Janssen, T.W., Rozendaal, L.A., 2001. Biomechanics and physiology in active manual wheelchair propulsion. Med. Eng. Phys. 23(10):713-733.

Van der Woude, L.H.V., van Croonenborg, J.J., Wolff, I., Dallmeijer, J. and Hollander, A.P., 1999. Physical work capacity after 7 weeks of wheelchair training : effect of intensity in able-bodied subjects. Med. Sci. Sports Exerc. 31(2):331-341.
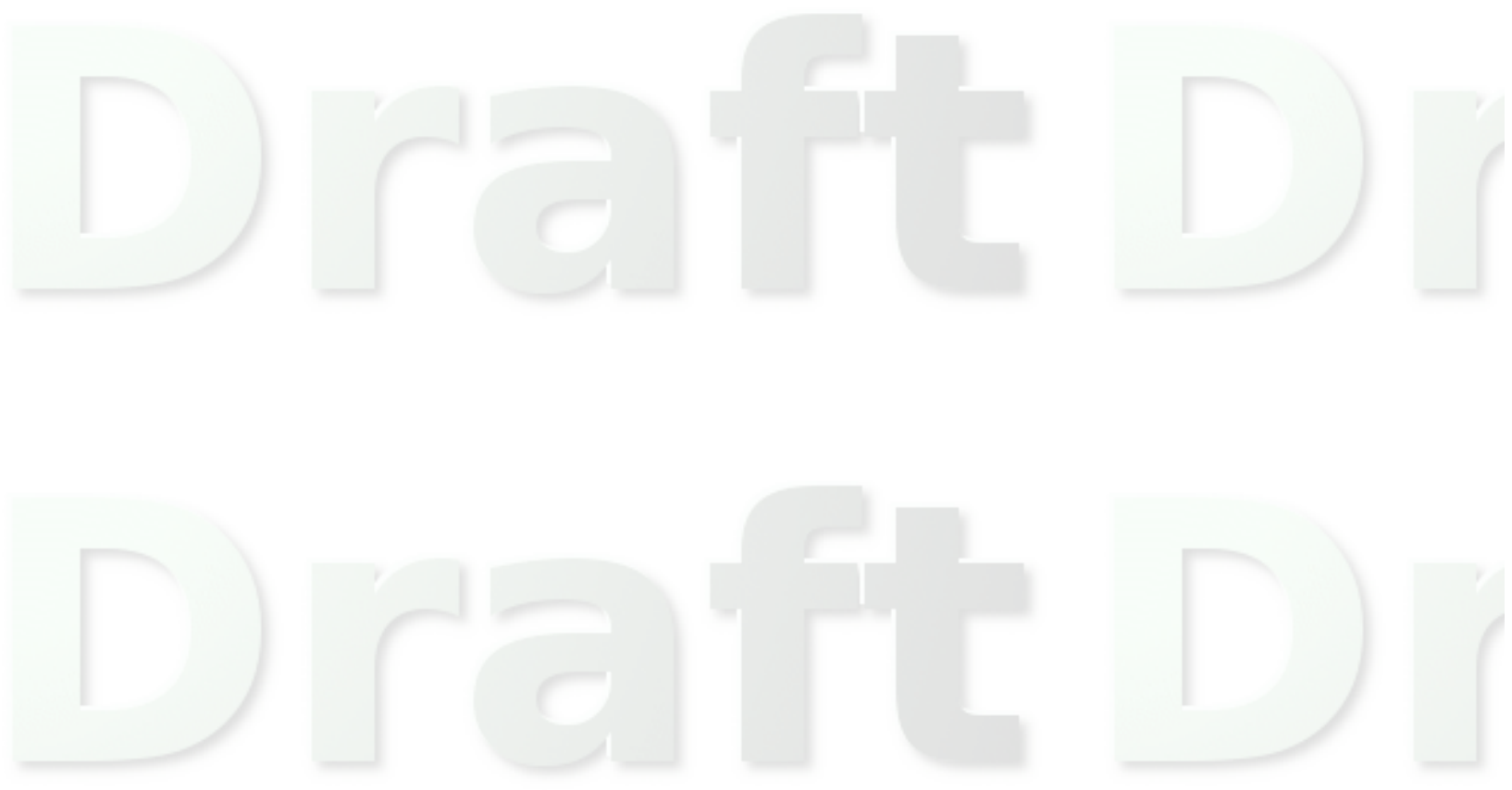